\title{
A CONSTRUÇÃO DA PERSONALIDADE NO PERÍODO DA ADOLESCÊNCIA DA CLASSE TRABALHADORA NA PERSPECTIVA DA PSICOLOGIA HISTÓRICO CULTURAL
}

\author{
THE CONSTRUCTION OF PERSONALITY IN THE ADOLESCENCE OF THE WORKING CLASS \\ UNDER THE PERSPECTIVE OF CULTURAL-HISTORICAL PSYCHOLOGY
}

'Acadêmica do Curso de Psicologia da UNIPAR - Universidade Paranaense, Campus Cascavel. E-mail: kabrustolin@hotmail.com. Endereço: Rua Suiça, 2702, Jardim Itália. CEP: 85.818-300.

${ }^{2}$ Acadêmica do Curso de Psicologia da UNIPAR - Universidade Paranaense, Campus Cascavel. E-mail: tarinebacarinalves@ hotmail.com. Endereço: Rua Sérgio Djamal de Hollanda, 1744, Neva. CEP: 85.802-230.

${ }^{3}$ Professora Mestre do Curso de Psicologia da UNIPAR - Universidade Paranaense, Campus Cascavel. E-mail: tatianesuperti@ prof.unipar.br. Endereço: Rua Fortaleza, 1740, Residencial Milano, Ap. 241, Centro. CEP: 85.810-051.
Karen Brustolin ${ }^{1}$

Tarine Bacarin Alves ${ }^{2}$

Tatiane Superti ${ }^{3}$

BRUSTOLIN, K.; ALVES, T. B.; SUPERTI, T. A construção da personalidade no período da adolescência da classe trabalhadora na perspectiva da psicologia histórico cultural. Akrópolis Umuarama, v. 26, n. 1, p. 45-57, jan./jun. 2018.

\section{DOI: 10.25110/akropolis.v26i1.6418}

Resumo: A presente pesquisa tem por intuito destacar e investigar a construção da personalidade no período da adolescência da classe trabalhadora embasado na Psicologia Histórico Cultural subsidiada pelo Materialismo Histórico Dialético. Este tema nos chamou atenção através das práticas de estágio em Centro de Referência e Assistência Social - CRAS de uma cidade do interior do Paraná. Com isso, pudemos destacar os aspectos que diferenciam as classes sociais, bem como as mediações que chegam até os adolescentes que residem neste contexto e que buscam formas de sobrevivência por meio do trabalho.

Palavras-chave: Adolescência, Classe Trabalhadora, Personalidade, Psicologia Histórico Cultural.

Aвstract: This study aims at highlighting and investigating the construction of personality in the adolescence under a Cultural-Historical Psychology perspective, supported by Dialectal Materialism. This topic has attracted attention after an internship experience at a Center of Reference and Social Assistance - CRSA in a city in the countryside of the state of Paraná. The authors were also able to highlight the aspects underlining social class differences, as well as the mediations that reach all the way to teenagers who live within that reality, who seek means of survival through work.

Keywords: Adolescence; Worker's class; Personality; CulturalHistorical Psychology. 


\section{INTRODUÇÃO}

Após a Revolução Russa, o primeiro país socialista encontrava-se diante de muitos desafios políticos, econômicos, sociais e culturais. Aos cientistas, pesquisadores e especialistas que ficaram no país deposita-se a tarefa de criar novos fundamentos da psicologia e da pedagogia soviética, com objetivo a formação do novo homem. Para formação desse novo homem, cria-se a necessidade de pensar ciência a partir de novos modos (PRESTES, 2010).

O período pós-revolução Russa foi de investimento em vários âmbitos e debate na ciência, inclusive na psicologia. Nesse período, os problemas da sociedade Russa se agravam, e Vigotski enxerga a necessidade do desenvolvimento de uma nova concepção de homem com o objetivo de superação das relações capitalistas. A luta de classes (burgueses e proletários) não desaparece com a abolição da propriedade privada dos meios de produção, ela se transforma a cada nova etapa da construção do socialismo na Rússia (TULESKI, 2008).

Segundo Lucci (p. 4, 2006) "Vigotsky surge na psicologia num momento significativo para a nação russa. Logo após ter-se consolidado a revolução, emerge uma sociedade que consequentemente exige a constituição de um novo homem". Vigotski via na construção de uma psicologia, com base marxista, o processo de construção de uma psicologia verdadeiramente científica e revolucionária. Entendia ser necessária a realização de uma mediação entre o materialismo histórico dialético e os estudos sobre os fenômenos psíquicos concretos. Portanto, estabeleceu um paralelo entre essa psicologia mediadora e o materialismo histórico de Marx, pois acreditava que este tinha o papel de desempenhar as mediações entre o materialismo histórico dialético e a análise das questões concretas, no caso, as questões concretas da história da sociedade e das formações sociais, como o capitalismo, por exemplo. Vigotski desejava uma teoria que significasse para a psicologia o que a obra O Capital de Marx, significa para a análise do capitalismo (DUARTE, 2000).

Vigotski afirmava que queria compreender na totalidade do método de Marx como se constrói a ciência, pois pretendia construir uma psicologia marxista e, para isso, era necessário a adoção do método em sua integralidade. Entendia que o desenvolvimento da ciência psico- lógica está relacionada ao processo de construção de uma sociedade socialista. Portanto, para criar a Psicologia Histórico Cultural, Vigotski fundamenta-se no Materialismo Histórico Dialético, contribuindo para a formação do novo homem revolucionário (DUARTE, 2000).

\begin{abstract}
Nossa ciência não podia nem pode desenvolver-se na velha sociedade [a sociedade capitalista]. Ser donos da verdade sobre a pessoa e da própria pessoa é impossível enquanto a humanidade não for dona da verdade sobre a sociedade e da própria sociedade. Pelo contrário, na nova sociedade [a sociedade socialista], nossa ciência se encontrará no centro da vida. $\mathrm{O}$ salto do reino da necessidade ao reino da liberdade formulará inevitavelmente a questão do domínio de nosso próprio ser, de subordiná-lo a nós mesmos (VIGOTSKI 1991, apud DUARTE , 2000, p. 82). ${ }^{4}$
\end{abstract}

O processo de transição do macaco ao homem passa por alguns estágios, estágios estes que se dividem dessa maneira: $O$ primeiro estágio trata-se da preparação biológica do homem, se inicia no fim do período terciário e da continuidade no início do quaternário. Os australopitecos levavam uma vida gregária, conheciam a posição vertical, utilizando-se de uma postura parcialmente ereta e utilizavam de instrumentos rudimentares, já possuíam uma comunicação entre si, mesmo que primitiva. Nesse estágio ainda reinam apenas as leis biológicas (LEONTIEV, 2004).

Quando os macacos deixam de utilizar as mãos apenas para se apoiar no chão ao caminhar e começam a utilizá-la para outros fins, como se pendurar nas árvores para colher e comer frutos, dá-se o passo definitivo para o inicio da transição do macaco em homem. A mão se tornando algo livre, pôde-se adaptar e, passo a passo, adquirir mais habilidades, flexibilidade, precisão, etc. Essas adaptações se transmitiam por hereditariedade e, a cada geração, se modificavam e aumentavam cada vez mais. (ENGELS, 2000)

O segundo estágio da evolução do macaco em homem possui uma série de etapas e pode designar-se como o estágio da passagem do macaco ao homem. Inicia com o aparecimento do pitecantropo até o homem de Neanderthal.

${ }^{4}$ Teoria e método em psicologia. São Paulo: Martins Fontes,1996. 
É marcado pelo início do uso de instrumentos e pelas primeiras formas de trabalho e sociedade, ainda que iniciais. $O$ homem ainda era regido por leis biológicas, transformando-se anatomicamente e transmitindo essas mudanças através da hereditariedade, mas, ao mesmo tempo, aparecem novos elementos na história do seu desenvolvimento. Começava-se aí, a partir do desenvolvimento do trabalho, a necessidade de comunicar-se pela linguagem, portanto, ocorreram modificações na constituição biológica do homem, tais como em seu cérebro, órgãos do sentido, sua mão, os órgãos da linguagem e etc. Resumindo, o desenvolvimento biológico do homem passa a se tornar dependente do desenvolvimento social. Assim, nasce o homem, em primeiro lugar regido por leis biológicas, com a adaptação dos órgãos às condições e necessidades de produção e, depois, por leis sócio-históricas, que regem o desenvolvimento da própria produção e todos os fenômenos que a compõe (LEONTIEV, 2004).

Observa-se, então, que todas as ações realizadas pelo homem advindas do trabalho requerem um conjunto de componentes orgânicos e sociais para que haja, então, uma relação com a natureza, nos processos de formação social, de modo que o homem transforma a natureza, e a natureza o transforma e o constrói por meio do trabalho. (ENGELS, 2000).

No último estágio da transição do macaco em homem, é onde surge o homem atual - Homo Sapiens, sendo o momento em que a evolução do homem se liberta totalmente das leis biológicas. Isso quer dizer que não há mais mudanças biológicas significativas. O desenvolvimento do homem, a partir desse momento, é regido por leis sócio-históricas (LEONTIEV, 2004).

Embora Vigotski concorde com a idéia da evolução, ele separa o comportamento dos animais e dos homens pela emergência da cultura e atribui um papel limitado à base genética do comportamento humano. Enquanto as leis biológicas explicam a evolução das espécies, são leis sócio-históricas que explicam o desenvolvimento do homem com inicio da cultura. (BRAGA, p. 22, 2010)

As diferenças entre os animais e os homens são que os animais apenas utilizam a natureza e produzem modificações nela somente por sua presença, já os homens dominam a natureza, fazem as modificações nela que julgam necessárias. Os animais agem para satisfazer as suas necessidades e os homens para produzir os meios de satisfazer as suas necessidades. $E$ é o trabalho que determina essa diferença (ENGELS, 2000).

Com essa base material exposta por Engels (2000) e Marx (LESSA; TONET, 2008), em que é por meio das relações de trabalho que o homem se constrói e constrói a natureza, que Vigotski utiliza-se do materialismo histórico dialético para subsidiar a formação de uma visão de homem para psicologia. Foi então que ele, juntamente com Lúria e Leontiev formam um grupo de pesquisa, na Universidade de Moscou, aperfeiçoando estudos na psicologia e pedagogia. Sendo assim, Vigotski e seus companheiros destacam a consciência embasados por Marx e Engels, concluindo que as estruturas da consciência humana são formadas pelas relações sociais e as condições expostas a ela (BRAGA, 2010).

Marx afirma que os homens só existem se transformam a natureza, por meio do trabaIho, sendo assim, sem o trabalho, a reprodução social não seria possível. Mesmo a natureza sendo dependente da reprodução social, isso não quer dizer que as leis que regem a natureza, regem também o homem. A vida social não é determinada por fatores biológicos, e sim por fatores sociais. O trabalho não só permite a transformação da natureza em sociedade, mas também permite que o homem se construa como indivíduo. Por meio do trabalho, o homem se torna um ser social, regido por leis de desenvolvimento completamente distintas das leis que regem os processos naturais. Sendo o trabalho do homem um processo consciente, diferentemente, dos animais que produzem suas ações por meio da hereditariedade (LESSA; TONET, 2008).

A distinção entre a evolução biológica e a evolução da história humana é baseada nos escritos de Marx e, principalmente, de Engels, com a explicação da transição do macaco em homem, a partir da teoria de Darwin. Percorrendo a história da evolução até o momento em que surge o Homo Sapiens (BRAGA, 2010).

Para Braga (2010), as funções psicológicas superiores ou culturais a partir de Vigotski, bem como a linguagem, capacidade de planejamento, atenção voluntária, fala, pensamento e entre outras funções, são construídas e trans- 
formadas qualitativamente. Já as funções, ditas elementares se determinam na evolução biológica. Sendo assim "[...]segundo Vigotski, não podem ser aplicados os mesmos princípios explicativos para os dois tipos de processo" (BRAGA, p. 22, 2010), desta forma Vigotski se baseou nos processos de mudanças, a partir da natureza social e da mediação por meio de signos.

É na mediação em que temos um comportamento indireto e mediado por meio de instrumentos e signos, ou seja, se não houver mediação, nosso comportamento será automaticamente realizado por meio de reflexos, de forma imediata e direta.

Comportamento mediado $=\mathrm{E}-\mathrm{M}-\mathrm{R}$

Comportamento não mediado $=\mathrm{E}-\mathrm{R}$

$\mathrm{E}=$ estímulo; $\mathrm{M}=$ mediação; $\mathrm{R}=$ resposta (BRAGA, 2010).

Quando falamos em instrumentos associamos às estruturas materiais, porém as próprias funções superiores podem ser instrumentos umas das outras, como por exemplo, acredita-se que a fala é um instrumento do pensamento, então pode se dizer que a fala é um instrumento de mediação para que haja uma resposta: o pensamento (BRAGA, 2010), bem como, temos o machado como instrumento material, que é utilizado para a execução da atividade humana: o trabalho (LESSA, TONET, 2008).

Os modos de mediação são fundamentais para a formação das funções psicológicas superiores, porém devemos salientar que vivemos em constante desenvolvimento social e natural, de modo que a natureza do homem se altera, o psiquismo se transforma, e a relação entre homem e sociedade vive em uma constante metamorfose, acarretando na mutação dos instrumentos e do uso deles (BRAGA, 2010).

A partir do breve exposto teórico a respeito da formação do homem, esta pesquisa tem por objeto de estudo a formação da personalidade na adolescência da classe trabalhadora. Assim temos como objetivo geral: compreender, na perspectiva da Psicologia Histórico Cultural a construção da personalidade na adolescência da classe trabalhadora. E como objetivos específicos: 1) Investigar o processo de formação da personalidade; 2) Estudar o período da adolescência para a Psicologia Histórico Cultural; 3) Compreender as classes sociais a partir do Materialismo Histórico Dialético.

Este estudo será pautado na pesquisa bibliográfica, tendo como principais referên- cias: Marx e Engels (2000; 2002; 2003), Engels (1988), Vigotski (1996), Leontiev (2004), Leal (2016), Braga (2010), Facci (2004), Martins (2004) e Netto (2011), contendo aspectos relacionados à construção da personalidade no período da adolescência, impactando no adolescente da classe trabalhadora.

A formação da personalidade é decorrente de uma relação dialética entre fatores internos e externos, através de relações entre as condições objetivas e subjetivas do indivíduo, que ao encontrar-se inserido nessa sociedade, se singulariza e se diferencia. As condições objetivas se referem às relações sociais do indivíduo, seu contato com outros indivíduos, com aquilo que é externo. $E$ as condições subjetivas se referem ao aparato biológico e à materialidade psicológica dos indivíduos, que se desenvolveram através da atividade social dele (MARTINS, 2001 apud SILVA, 2009).

Sendo assim, a personalidade de cada indivíduo não se forma isoladamente, mas sim, a partir do resultado da atividade social, não dependendo dos indivíduos individualmente ou separadamente, e sim das relações que se estabelecem entre eles (MARTINS, 2004).

A adolescência é caracterizada por uma passagem da etapa infantil para a etapa da adolescência, de modo que os adolescentes passam por crises entendidas como crise dos 13 (puberdade - 14 aos 18 anos) e crise dos 17 . As crises podem alterar a personalidade do indivíduo, bem como causar mudanças bruscas em seu comportamento, marcadas pelo negativismo nas exigências a serem cumpridas, entrando, por vezes, em conflito com os adultos. As crises são identificadas como um processo dialético pelo qual se apresentam como uma necessidade de mudanças internas que se originam na superação de uma etapa e contradição do modo de vida (FACCI, 2004).

É no período da adolescência em que ocorrem inúmeras mudanças biológicas e físicas no corpo do indivíduo, porém não se pode reduzir o entendimento a esta etapa apenas por essas mudanças, segundo a Psicologia Histórico Cultural. O adolescente é visto, a partir dessa perspectiva, como um ser social e histórico, pois "[...] as leis biológicas e as características determinantes do desenvolvimento humano pautadas na hereditariedade não são mais as forças motrizes do desenvolvimento humano, pois cederam lugar às leis sócio-históricas." (ANJOS, 2014, p. 
07).

Portanto, foi por meio das práticas de estágio em Centro de Referência e Assistência Social, na zona rural de uma cidade do interior do Paraná, nas quais ocorrem atividades com adolescentes que, em sua maioria, pertencem à classe trabalhadora, que surgiu o interesse em compreender como ocorre a formação da personalidade dos adolescentes, que compõe essa classe.

Este estudo justifica-se, considerando a concepção de adolescência da psicologia tradicional que, em geral, está embasada em uma visão biológica, naturalizante e patologizante dos indivíduos. As contribuições da Psicologia Histórico Cultural e dessa pesquisa são de não naturalizar a adolescência, pois esta é um período do desenvolvimento e tem um caráter histórico e de classe como todo o fenômeno humano. Ainda, objetiva-se também propagar a verdadeira base da Psicologia Histórico Cultural, como sendo uma base marxista, que por muito tempo foi disseminada por vários países, inclusive no Brasil, com uma visão dissociada do materialismo histórico dialético de Marx.

Desse modo, essa pesquisa visa a contribuir na produção de novas formas de atendimento aos adolescentes, este sendo compatível com a realidade em que se encontram, buscando entender os indivíduos naquilo que verdadeiramente os compõe, bem como nossas contribuições acerca do assunto pesquisado, pois não há bibliográficas nesta totalidade.

\section{A CONSTRUÇÃO DA PERSONALIDADE PARA A PSICOLOGIA HISTÓRICO CULTURAL}

É fato que existe no homem uma singularidade, porém a existência dessa singularidade provém irredutivelmente de uma construção genérica. $\mathrm{O}$ homem apenas se torna um ser individualizado a partir do processo histórico e social, ou seja, é um ser social e singular exatamente por ser um ser social genérico. Para compreendermos o indivíduo, precisamos entender que o homem é indissociável de seu gênero humano (MARTINS, 2004).

A personalidade é então um processo que resulta das relações entre as condições sociais e condições psíquicas do indivíduo, que, ao encontrar-se inserido em uma sociedade, se individualiza e diferencia, tornando-se único (SILVA, 2009).
Segundo Martins (2004, p. 84):

\begin{abstract}
Essas condições representam as bases a partir das quais, ao longo de uma histórica evolução, desenvolve-se, por meio da atividade, o psiquismo humano. A atividade humana, que por sua natureza é consciente, determina nas diversas formas de sua manifestação a formação de capacidades, motivos, finalidades, sentidos, sentimentos etc., enfim engendra um conjunto de processos pelos quais o indivíduo adquire existência psicológica.
\end{abstract}

Para a Psicologia Histórico Cultural, a personalidade é entendida como um fruto da atividade individual, seja ela em qualquer período de vida. Na adolescência, por exemplo, a atividade principal é compreendida pela totalidade social em que o indivíduo está inserido, sendo esta a comunicação social, resultado de suas relações objetivas e subjetivas, diferenciando cada indivíduo, por meio de suas relações, o que produz personalidade (MARTINS, 2004 apud CABRERA, 2014).

Remete ao plano da pessoa, do homem como ser social, "que faz, pensa e sente, e é neste plano que nos deparamos com a personalidade", portanto, "a ciência da personalidade é a ciência da vida real dos indivíduos, pela qual constroem uma maneira particular de funcionamento" (MARTINS, 2004, p.84, apud CABRERA, 2014, p. 9).

Assim, a personalidade não pode ser descolada da atividade principal de cada período, pois, ela só irá se construir, através das relações obtidas por meio do desenvolvimento causado pela atividade principal. Assim, acredita-se que a atividade principal, juntamente com a personalidade, não está ligada exclusivamente à genética e sim aos resultados compostos neste desenvolvimento psíquico (LEONTIEV, 1979 apud CABRERA, 2014).

Dessa forma, para Elkonin (1987) apud Facci e Reis (2014), é no período da adolescência, em que podemos esclarecer a atividade principal, como a comunicação íntima pessoal. O adolescente, por sua vez, desenvolverá diferentes relações com os adultos, ampliando críticas acerca de suas relações e contradições presentes nela, como imagem de si e do outro 
na sociedade, diferenciando-se do período da infância. Neste período, a atividade de estudo (atividade dominante) permanece juntamente com a comunicação pessoal (atividade principal), intensificando a junção das duas, através da relação externa dos adolescentes para com o mundo adulto, grupos de amigos e lazer aos quais mantém diferentes regras compostas por valores éticos e morais, não direcionando somente suas relações em âmbito familiar, "[...] o desenvolvimento do adolescente depende de muitas condições e, por isso, pode se dar de maneira desigual, coexistindo aspectos da infância e da vida adulta." (PETROVISKI, 1979 apud FACCI, REIS 2011, p. 7).

A personalidade é considerada por Vigotski (1996) apud Facci e Reis (2011) uma estrutura psíquica a qual decorre de um processo dialético, por meio de crises existentes de um período ao outro em que ocorrem de forma diferente de indivíduo para indivíduo, por meio das apropriações culturais existentes nas relações sociais que o cercam. "A personalidade incide em envolver o ser humano como decorrência de um processo histórico, no qual o biológico é decomposto pelas relações sociais que se estabelecem, compondo as funções psíquicas e a consciência humana" (CABRERA, 2014, p.22).

O desenvolvimento humano ocorre por meio dos períodos que são caracterizados por uma atividade principal ou dominante. A atividade dominante é aquela que possibilita que os processos psíquicos tomem forma ou se reorganizem, e a qual permite as mudanças mais importantes. $\mathrm{E}$ a atividade principal diz respeito à relação que se estabelece entre o indivíduo e o meio, o qual é característico, específico em cada período, contribuindo para o desenvolvimento humano (LEONTIEV, 1987 apud REIS; FACCI, 2015).

Esses períodos são influenciados por novas formações que determinam o curso de desenvolvimento humano. Essas novas formações são a estrutura da personalidade, que conduz o processo do desenvolvimento. Para que se possa compreender algum determinado período do desenvolvimento, é necessário que se faça uma análise dos processos de mudança da estrutura da personalidade (VIGOTSKI, 1996 apud REIS; FACCI, 2015).

\section{AADOLESCÊNCIA PARA A PSICOLOGIA HIS- TÓRICO CULTURAL}

Baseando-se em Vigostski e Luria, grandes nomes da psicologia Histórico Cultural, acredita-se que o ser humano vai além de uma perspectiva biológica. Deve-se observar os aspectos externos e como estes são interiorizados na consciência, por meio de sua vida social, sendo ela dialética. Leontiev ainda ressalta a grande importância voltada ao contexto escolar, de modo que é por meio da educação escolar e seus progressos que se enriquecem as práticas sociais e históricas (LEONTIEV, 1978; VIGOTSKI, 1997; LURIA, 1986 apud LEAL, 2016).

A educação escolar agrega muitos avanços no indivíduo, principalmente, em seu psiquismo, estabelecendo relações de mediação entre realidade, através da educação formal e individual, pela qual tem papel fundamental na criação de instrumentos que auxiliem na interpretação da realidade social. Portanto, é por meio de conteúdos teóricos que o psiquismo irá se desenvolver, porém a escola se limita muito a conteúdos tradicionais, esquecendo que vivemos em uma realidade dialética, havendo contradições e injustiças a todo momento, o que acarreta a uma alienação (LEAL, 2016).

Não se deve excluir a ideia de que a educação escolar acarreta na transformação da consciência, porém nos moldes capitalistas, ou seja, se a escola aderisse a uma educação fundamentada nas contradições e desigualdade social decorrentes na atualidade isso resultaria em uma luta pela transformação social (LEAL, 2016).

Para a Psicologia Histórico Cultural, a adolescência é um período de suma importância, pois é neste momento em que o indivíduo começa a formar conceitos, ocorrendo mudanças de grande importância para o psiquismo. Assim, não se deve reduzir a adolescência somente às mudanças biológicas, como é abordado em algumas teorias, naturalizando este período (LEAL, 2016).

Adolescência é um assunto muito problematizado na atualidade, mas nem sempre foi assim, durante muito tempo, acreditava-se que após a infância os indivíduos se tornavam adultos, excluindo o período de puberdade, ou seja, a infância era muito vinculada as questões de dependência, portando a criança se tornaria adulto após se atingir a independência (LEAL, 
2016).

A adolescência passa a ser percebida após o século XIX, por meio da escolarização, pelo qual afastava-os do mundo do trabalho. Porém, esse impacto de percepção a este período passa a ser fomentado após a segunda guerra mundial, em que, apresenta-se a adolescência como uma fase de amadurecimento, sendo ele de fatores biológicos, pelo qual os adolescentes entram em conflitos internos, ressoando socialmente, através de diferentes comportamentos (LEAL, 2016).

O histórico da adolescência refletido por meio de aspectos sociais revela este período como natural e similar para todos. Todavia, o adolescente é um ser histórico e cultural, pelo qual se constrói através das superações das contradições, revivendo o mesmo percurso, porém renovando e reinventando seus comportamentos, sendo este processo necessário para seu desenvolvimento (LEAL, 2016).

Para muitos autores, a adolescência é vista como um período negativo, rodeado de fatores biológicos, excluindo fatores, sociais, culturais, históricos e econômicos, por que, desta maneira, o conteúdo em questão seria desviado. Ou seja, o adolescente passa por um comportamento patológico, sendo ele normal, como um ser evolutivo. Os aspectos de rebeldia seriam entendidos como uma falta infantil e a quebra de dependência, sendo caracterizado como uma síndrome normal da adolescência. Neste período, acontece o processo da formação da identidade, em que os adolescentes têm receio do que os outros pensam dele, ocorrendo um conflito de identidade. "Este movimento contextualiza a adolescência como fenômeno histórico e social, como construção cultural marcada pelas concepções que se tornaram hegemônicas, influenciando profundamente o comportamento dos jovens" (LEAL, 2016, p. 19).

Leal (2016) apresenta muitas críticas a essas teorias, pois sem as relações sociais que compõe o desenvolvimento do homem, todos os indivíduos reproduziriam os mesmos comportamentos por serem fatores inatos. Portanto, é por meio de inúmeras informações naturalizadas, destacando o que é a adolescência, sendo esta de rebeldia e desequilíbrios de comportamentos, que os próprios adolescentes acabam internalizando e reproduzindo tais ações vistas socialmente. não superando este conceito naturalizado, ao qual não causa favorecimento para uma nova visão.

Para se entender a adolescência, é necessário entender a relação entre adulto e adolescente, ou seja, os comportamentos presentes nesta relação e as maneiras de mediação atribuídas a ela, pois, deste modo, é possível observar no adolescente sua inserção socialmente em grupos de seu interesse, pelas quais estão inteiramente ligadas a aspectos históricos, culturais, políticos apresentados ao indivíduo a serem interiorizados, acarretando no seu desenvolvimento (LEAL, 2016).

$\mathrm{Na}$ sociedade atual, tanto a criança quanto $o$ adolescente, neste período, passam por um processo "adaptativo", ou seja, seus comportamentos devem ser encaixados ao contexto atual, como um treinamento para iniciar a fase adulta. Então, o adolescente é visto como uma máquina, sendo controlado por ideias sociais, perpassando as instruções a família/educadores (LEAL, 2016).

Leal (2016), por meio de leituras realizadas nas pesquisas de Bock (2004), destaca que a adolescência vista socialmente e, por vezes, naturalizada, até mesmo pela psicologia, causa desvalorização do período, pelo qual os jovens querem ganhar sua liberdade e, por vezes, entram em conflito com seus pais que não querem perder o controle sobre eles, o que acarreta em comportamentos naturais ditados socialmente, sendo esta uma reprodução social.

É necessário observar a quais condições esses jovens vivem, pois elas também refletem ao seu desenvolvimento e a suas crises de identidade. A busca de si mesmo e seu encontro em grupos que Ihe são atrativos (BOCK, 2007 apud LEAL, 2016).

É importante destacar que, embora a adolescência seja tomada como fenômeno universal e único, terá marcas diferentes, em diferentes grupos e classes sociais, pois a sociedade de classes em que vivemos não permite acesso aos bens culturais de forma igualitária a todos e a grande maioria não tem acesso à grande parte dos bens produzidos, fator que influencia no desenvolvimento dos indivíduos, acarretando formas diferentes e peculiares de viver a adolescência, que se manifestará de maneira singular nos diferentes segmentos sociais. (LEAL, p. 23, 2016) 
É então na psicologia histórico cultural que surge a necessidade de superação de algumas teorias voltadas a modelos adaptativos. Sendo o homem como ser histórico e cultural (FACCI, 2004; ELKONIN, 1987 apud LEAL, 2016).

Todavia, o indivíduo no período da adolescência passa por mudanças biológicas, físicas e, essencialmente, por mudanças sociais. Como estas relações são mediadas e de que maneira refletem em seu psiquismo? (ELKONIN, 1987 apud LEAL, 2016).

Bem como, a psicologia em uma série de teorias reduz a adolescência a uma fase maturacional (puberdade), ocorrendo mudanças biológicas e fisiológicas, o que por vezes não se deve deixar de lado, entretanto deve-se analisar o que há por trás desses aspectos, quais fatos externos podem favorecer para uma investigação eficaz desse período, não analisando como um conjunto de sintomas pertencentes a certo período (VYGOTSKI, 1996 apud LEAL, 2016).

Segundo Facci (2004), o desenvolvimento é marcado por estágios, cada um deles é definido por uma atividade principal, que é a principal forma de relacionamento do indivíduo com a realidade. Através dessas atividades principais, a criança se relaciona com o mundo a sua volta e em cada um dos estágios se formam necessidades específicas em seu psíquico.

Apesar de cada período do desenvolvimento ter uma atividade principal, no próximo período, ela não deixa de existir, ela apenas dá o lugar de atividade principal a outras atividades. Novos motivos surgem e, a partir disso, é preciso que uma nova atividade se estabeleça, para que o desenvolvimento dê continuidade (ELKONIN, 1987 apud REIS; FACCI, 2015).

O que marca essa passagem de um período para outro são as crises. E é a crise que delimita, quando um período se encerra e quando dá-se início a outro (ELKONIN, 1987 apud REIS; FACCI, 2015).

A passagem de um estágio do desenvolvimento para outro ocorre quando a criança começa a se dar conta que o lugar que ocupava nas relações sociais ao seu redor e que esse espaço não corresponde mais às suas potencialidades naquele momento e, movimentando-se para modificar, surgem as contradições. Ela tem consciência das relações sociais que estabelecia anteriormente e isso faz com que busque uma mudança na motivação de sua atividade e, a partir disso, nascem novos motivos, levando-a a uma nova interpretação de suas ações do passado. A atividade que antes era determinada como atividade principal passa a ser segundo plano, dando lugar a uma nova atividade dominante que vai dar início ao novo estágio do desenvolvimento (LEONTIEV, 1998 apud FACCI, 2004).

Neste período, o indivíduo começa a se interessar por novas coisas, ter novos hábitos, tendo mudanças muito visíveis em seus comportamentos, sendo o que determina este período. Dessa forma, o adolescente deverá internalizar esse novo processo, ao qual antes era externo, desenvolvendo seu pensamento. "Os novos estímulos surgidos nessa etapa impulsionam o desenvolvimento e os mecanismos do pensamento" (LEAL, p. 27, 2016).

$\mathrm{Na}$ adolescência, o indivíduo passa por esses processos descontentes e conflituosos, nesse período de crise, entre um estágio de desenvolvimento e outro, sendo estes ocorrentes de forma dialética, superando as contradições, constituindo uma etapa em que o indivíduo cria suas críticas revolucionárias, construindo assim a sua personalidade (LEAL, 2016).

É por meio das relações sociais em que o indivíduo transforma seu conteúdo social em individual, ou seja, na passagem de uma idade para a outra, a consciência se modifica, por meio das diferentes formas de atividade, compostas por um conjunto de dinâmicas de desenvolvimento (LEAL, 2016).

A chegada da adolescência acontece com a atividade principal de comunicação íntima pessoal entre os adolescentes. Ocorre uma mudança com relação à posição que o adolescente ocupa em relação ao adulto, junto aos conhecimentos que ele possui e suas capacidades. Em alguns casos, colocam-no como igual aos adultos e, em alguns casos em particular, até como alguém superior aos adultos. $O$ adolescente torna-se crítico, com as exigências que lhe são impostas, modos de agir, qualidades pessoais dos adultos e com os conhecimentos teóricos. Ele busca, na relação com os outros adolescentes um posicionamento diante das questões que realidade impõe a sua vida (FACCl, 2004).

O estágio da adolescência é o mais crítico, pois, nessa idade, a atividade principal é a relação pessoal íntima, que os adolescentes ao se relacionarem entre si encontram uma forma de reproduzir as relações entre os adultos. A in- 
teração com o grupo é mediada e determinada por normas e regras do grupo. O estudo ainda é considerado uma atividade importante para esse período e ocorre o domínio da estrutura geral da atividade de estudo naqueles que são alunos, a formação do caráter voluntário, tomada de consciência das particularidades individuais de trabaIho e a utilização dessa atividade para organizar as interseções com os outros alunos (FACCl, 2004).

É nessa fase do desenvolvimento que se produz no adolescente um avanço no desenvolvimento intelectual, formando os conceitos. O pensamento por conceito proporciona para os adolescentes uma consciência social, e o conhecimento da ciência, arte e diversos outros conhecimentos na esfera cultural podem ser assimilados. Através do pensamento por conceito, o adolescente consegue compreender a realidade em que ele vive, as pessoas ao seu redor e a si. O pensamento concreto passa a dar seu lugar ao pensamento abstrato e o conteúdo do pensamento do adolescente se transforma em convicção internalizada, orientação de seus interesses, em normas, em sentido ético, em seus desejos e seus objetivos. (VYGOTSKI, 1996 apud FACCI, 2004)

$A$ adolescência é um período muito importante no desenvolvimento do indivíduo, pois é nela que se formam as funções psicológicas superiores, a formação dos conceitos, o pensamento abstrato, que vão permitir com que o adolescente compreenda a realidade e também que forme uma concepção do mundo e de si (LEAL, 2016).

Por meio da comunicação pessoal com seus iguais, o adolescente forma os pontos de vista gerais sobre o mundo, sobre as relações entre as pessoas, sobre o próprio futuro e estrutura-se o sentido pessoal da vida. Esse comportamento em grupo ainda dá origem a novas tarefas e motivos de atividade dirigida ao futuro, e adquire o caráter de atividade profissional/de estudo. (FACCI, 2004 p. 71)

Por meio da socialização e da comunicação, o adolescente desenvolve opinião acerca do mundo, das relações e do futuro. $E$ a partir disso, que em grupo, por meio da linguagem, surgem novas tarefas e motivos que dizem respeito ao futuro. Estabelecendo-se então a ati- vidade dominante profissional de estudo, que possibilitará que o adolescente pense sobre sua escolha profissional. (PETROVISKI, 1979 apud REIS; FACCI, 2015).

$\mathrm{Na}$ idade escolar avançada, a atividade de estudo é utilizada para o adolescente como um meio de orientação e preparação para a profissão futura. O adolescente possui o domínio dos meios de atividade de estudo autônomo, com uma atividade cognoscitiva e investigativa criadora. E a etapa final do desenvolvimento acontece quando o indivíduo torna-se trabalhador (DAVIDOV; MÁRKOVA, 1987 apud FACCI, 2004).

Quando estiver inserido no mundo do trabalho, o adolescente se tornará adulto. $\mathrm{O}$ trabalho torna-se sua nova atividade dominante. O adulto, por meio do trabalho, possui um novo lugar na sociedade, e suas relações ocorrem e se processam de modo diferente das anteriores. Ocupa o lugar central da estrutura social e evolutiva da sociedade, pois é o principal equipamento de transmissão do mecanismo estatal, social e econômico. E, apesar de o trabalho ser a sua atividade dominante, nem sempre a realização desse trabalho se dá de maneira igualitária nas sociedades capitalistas (PRETOVISKI, 1979; TOLSTIJ, 1989 apud REIS; FACCI, 2015).

\section{CLASSES SOCIAIS: PRIMEIRAS REFLEXÕES}

Para Netto (2011), pautado no Materialismo Histórico Dialético, acredita-se que as classes sociais surgem desde o feudalismo, de modo que havia uma divisão de afazeres e lucro, ou seja, os senhores feudais permaneciam com a maior parte da produção, executada pelos homens que usufruíam se suas terras. Posteriormente, o conceito de classes fica mais nítido, por meio da divisão de poderes advindas do capitalismo, a partir dos modos de produção, quando a propriedade privada ganha espaço socialmente, e surge a necessidade da divisão do trabalho.

[...] neste novo modo de produção a divisão do trabalho se dá entre quem concede e quem executa o trabalho, ou seja, entre quem tem a posse da propriedade e os meios de produção e quem vai operar diretamente na produção de tais mercadorias. (NETTO, p. 5, 2011).

Entretanto, essa divisão causa impacto na classe trabalhadora. A manufatura, exercida 
pelo atual proletariado não é mais interessante para o capitalismo, pois a execução desta produção era lenta demais comparada à indústria moderna, a qual executava o trabalho em menor tempo e custo (MARX; ENGELS, 2003). É neste momento em que a burguesia utiliza-se do Estado, como um instrumento de domínio de outras classes, organizando os negócios comuns para toda a burguesia. Neste sentido, percebe-se o reflexo do capitalismo na definição de classes, pois, "Há sempre uma relação de oposição entre duas classes, de modo que uma não existe sem a outra" (NETTO, p. 5, 2011).

Podemos entender esta divisão de classes, observando as duas classes opostas, desde processo criado por meio do capitalismo. Sendo então a classe burguesa, a detentora de capital, dona de propriedades que empregam o proletariado. Entende-se por proletariado, aqueles pertencentes à classe trabalhadora, "não tendo meios próprios de produção são obrigados a vender sua força de trabalho para sobreviverem" (ENGELS, 1888 apud MARX; ENGELS p. 26, 2003).

Assim, surgem conflitos entre a classe burguesa e proletariado, devido às ideais, aos objetivos e às diferentes necessidades, sendo entendidas como a luta de classes, pois a classe dominante fazia da classe dominada um objeto de alienação, por meio da produção, havendo uma contradição muito grande daquele que produz e daquele que consome (NETTO, 2011).

Com o desenvolvimento da burguesia, isto é, do capital, desenvolve-se também o proletariado, a classe dos operários modernos, que só podem viver se encontrarem trabalho, e que só encontram trabalho na medida em que este aumenta o capital. Esses operários obrigados a vender-se diariamente, são mercadoria, artigo de comércio, como qualquer outro; em consequência, estão sujeitos a todas as vicissitudes da concorrência, a todas as flutuações do mercado. (MARX; ENGELS, 2000).

Dessa forma, os homens dessa classe deveriam se adaptar às condições em que os meios de produção e a classe burguesa executavam sobre eles, com o intuito de crescer seu capital e reduzir os salários a níveis extremamente baixos, aumentando assim a carga de trabalho devido à concorrência de mercado o que "[...] torna a condição de vida do operário cada vez mais precária [...]" (ENGELS; MARX, p. 48 2002).
Neste sentido, a classe burguesa, quebra todo e qualquer vínculo cultural em prol do capitalismo, bem como o sentimento de família, na qual desde cedo, os filhos saiam de casa para sua sobrevivência futura, artimanha utilizada pela indústria moderna, em que recorre à a força de trabalho como arma de produção (MARX; ENGELS, 2003).

Levando em consideração esses aspectos, entende-se, portanto, que as classes sociais, são diferenciadas, a partir do lugar em que cada indivíduo ocupa socialmente e historicamente, através da divisão do trabalho e a obtenção de capital adquiridas por ele, diferenciando-se o seu espaço no sistema econômico (LÊNIN, 1980).

Marx e Engels (2003) criticam o capitalismo, pois há uma relação antagônica de interesses e exploração entre classe trabalhadora e burguesia, pois enquanto o proletariado busca por melhores condições de trabalho e sobrevivência, a burguesia procura meios para o aumento de capital. Assim sendo, se os burgueses atenderem aos ideais do proletariado, a classe burguesa não almejará o capital esperado.

\section{CONSIDERAÇÕES FINAIS}

Levando-se em consideração os aspectos apresentados anteriormente, pode-se observar que o homem é síntese das relações sociais de determinado momento histórico, pois se constrói por meio de suas relações sociais e contexto em que está inserido. Desse modo, cada indivíduo, se constrói de maneira diferente, devido às formas de mediação apresentadas a ele, ou seja, ocorrerão apropriações diferenciadas de indivíduo para indivíduo. Assim, entende-se a construção de homem através do trabaIho, diferenciando-o dos animais, pois o homem transforma a natureza, produzindo instrumentos a partir da sua necessidade, tornando-o um ser social; já os animais apenas saciam suas necessidades, agindo por reflexos/instintos, sem ter consciência.

A partir do Homo Sapiens, as mudanças morfológicas não são mais significativas. Não é mais o biológico que dita o desenvolvimento, deixa de ser algo inato, hereditário, por seleção e adaptação dos animais (das espécies) e passa a ser um desenvolvimento a nível histórico e social, não há mais mudanças biológicas significativas. O homem age de forma intencional, 
transformando a natureza por meio do trabalho. A partir da transformação do meio, criamos a cultura e assim toda a nossa história fica registrada por meio da cultura.

O homem é um considerado um ser histórico cultural devido as suas apropriações adquiridas ao longo da história. A apropriação é o contato de forma mediada, por meio das relações sociais, e ativa com a cultura. A atividade humana se encarna em objetos e é necessário que o indivíduo tenha uma atividade com esses objetos para poder se apropriar. A organização interna desses conteúdos se dá pela generalização, que é a transposição dos vínculos - uma abstração ligada a outras abstrações - da realidade concreta para a realidade interna, é a categorização da realidade. Sendo assim, a função da generalização é categorizar internamente a realidade externa. Só nos tornamos humanos quando temos generalizado o processo histórico acumulado. E esse processo de apropriação e generalização acontece de forma dialética.

Essas apropriações ocorrem por meio das formas de mediação proporcionadas a cada indivíduo, ou seja, havendo um estímulo advindo da necessidade de algo, o indivíduo será exposto a alguma forma de mediação através de instrumentos, posteriormente ocorrendo uma resposta $(E-M-R)$, entretanto, não de uma maneira mecanicista e sim dialética, pois a natureza se transforma constantemente, bem como o homem. Como por exemplo, no período da adolescência os adolescentes sentem maior necessidade de apropriações voltadas ao mundo adulto, de como manejar diferentes tipos de responsabilidades, portanto, o estímulo seria esta necessidade. Para este estímulo, são necessárias formas de mediação, podendo ser identificado para este período como instrumento a educação formal: escola, livros, utensílios voltados ao estudo, tendo como resposta o pensamento por conceito, porta de entrada para diferentes tipos de apropriações. Entretanto, devemos destacar que este processo ocorrerá de formas diferentes para cada adolescente, devido à sua realidade e condições que subsidiem os modos inserção social/cultural.

Negamos então a adolescência como um processo natural e a compreendemos como uma reposta histórica, pois como dito anteriormente o homem é um ser histórico e cultural, que desenvolve-se à partir das apropriações dos objetos culturais que lhe são ofertados.
Sendo assim, ocorrem diferenças no processo de desenvolvimento dos adolescentes da classe trabalhadora com relação aos adolescentes da classe burguesa.

Para entendermos essa diferença, precisamos responder a pergunta: Quais são as riquezas culturais garantidas aos adolescentes da classe trabalhadora? Os adolescentes da classe burguesa têm acesso a todas as apropriações necessárias para o desenvolvimento pleno das funções psicológicas superiores, tendo acesso à educação formal de qualidade, cultura, lazer, saúde e etc.? Enquanto a adolescência da classe trabalhadora é marcada por apropriações que garantem apenas a reprodução da força de trabalho barata, pois a sociedade capitalista em que vivemos empurra esses adolescentes para o mundo do trabalho, de maneira que são colocados no meio de uma busca por condições de sobrevivência e a educação formal. Não sendo possível aproximar-se da segunda opção, pois há a necessidade do trabalho e no que tange à esfera das políticas públicas lhe é ofertado o mínimo para que ocorra a manutenção de sua força de trabalho e para que esses adolescentes continuem com a necessidade de vender sua mão de obra barata por questões de sobrevivência.

Assim, o adolescente da classe burguesa encontra-se no desenvolvimento pleno das suas funções psíquicas superiores, por meio da atividade principal de relação íntima pessoal e a educação formal, formando o pensamento por conceitos e preparando-se para entrar no mundo do trabalho na fase adulta. Já o adolescente da classe trabalhadora tem sua atividade principal substituída pela atividade do trabalho, não entrando em contato com os conceitos científicos que a educação formal oportuniza. Isso prejudica o desenvolvimento de suas funções psíquicas superiores, pois nesse estágio do desenvolvimento dos adolescentes está formando-se o pensamento por conceitos. Porém ele não entra em contato com todas as apropriações necessárias para que desenvolva seu pensamento crítico.

A personalidade se forma então, mediante a pobreza cultural, que é destinada à esta classe, suscitando a dificuldade de pensar sobre si mesmo, os demais, e a própria sociedade. Isso constrói um adolescente alienado, ou melhor, um trabalhador alienado. Porém, apesar da alienação ser ordem na formação dos adoles- 
centes dessa classe, ela é passível de mudança, por meio da ressignificação, e entrando em contato com novos conceitos, esse adolescente poderá se tornar um sujeito consciente e crítico acerca da sociedade, das suas condições concretas de trabalho e de vida.

\section{REFERÊNCIAS}

ANJOS, R. E. Aportes teóricos da Psicologia Histórico-Cultural à educação escolar de adolescentes. 2014. Disponível em: <http://www. histedbr.fe.unicamp.br/acer_histedbr/jornada/ jornada11/artigos/3/artigo_simposio_3_671_ricardo.eleuterio@hotmail.com.pdf> Acesso em: 15 jun. 2017.

BRAGA, E. S. História da Pedagogia. Revista Educação. São Paulo: editora Segmento, p. 2029, 2010.

CABRERA, T. L. REFLEXÕES ACERCA DO CONCEITO DE PERSONALIDADE: ABORDAGENS HISTÓRICO CULTURAL COM BASE EM LEONTIEV. (Trabalho de Conclusão de Curso). Maringá, 2014. Disponível em: <http://www.dfe. uem.br/TCC-2014/TAMIRES-LAYLA_CABRERA.pdf>. Acesso em: 23 jul. 2017.

DUARTE, N. A anatomia do homem é a chave da anatomia do macaco: a dialética em Vigotski e em Marx e a questão do saber objetivo na educação escolar. Educ. Soc., Campinas, v. 21, n. 71, 2000. Disponível em: <http://www. scielo.br/pdf/es/v21n71/a04v2171.pdf>. Acesso em: 22 maio 2017.

ENGELS, F. A dialética da natureza. São PauIo, Editora Paz e Terra, ed. 6, 2000.

FACCI, M. G. D. A periodização do desenvolvimento psicológico individual na perspectiva de Leontiev, Elkonin e Vigostski. Cad. Cedes, Campinas, vol. 24, n. 62, p. 64-81, abril 2004.

FACCI, M. G. D.; XAVIER, L. A. O conceito de personalidade: Uma análise a partir da psicologia histórico-cultural. In: X CONPE - Congresso Nacional de Psicologia, 10, 2011, Maringá. Anais... Maringá: ABRAPEE, 2011. Disponível em: <http://www.abrapee.psc.br/xconpe/trabalhos/1/155.pdf>. Acesso em: 16 jul. 2017.

LEAL, Z. F. R. G. Adolescência, Educação Es- colar e Constituição da Consciência: Um estudo sob a perspectiva da Psicologia Histórico-Cultural. Editora da Universidade Estadual de Maringá, 2016.

LÊNIN, V. I. Uma grande iniciativa. Vol. 3. São Paulo: Editora Alfa Omega, 1980.

LUCCI, M. A. A proposta de Vygotsky: a psicologia sócio - histórica. Profesorado. Revista de currículum y formación del profesorado, 10, 2 (2006). Disponível em: <http://www.ugr. es/ recfpro/rev102COL2port.pdf>. Acesso em: 5 maio 2017.

LESSA, S.; TONET, I. Introdução à filosofia de Marx. São Paulo, Expressão Popular, 2008.

LEONTIEV, A. L. Desenvolvimento do psiquismo. São Paulo: Centauro, 2004.

MARTINS, L. M. A natureza histórico-social da personalidade. Cad. CEDES, Campinas, v. 24, n. 62, 2004. Disponível em: <http://www.ccp.uenp. edu.br/dirposgrad/gepem/texts/gepem070-021. pdf>. Acesso em: 15 jun. 2017.

MARX, K.; ENGELS, F. Manifesto Comunista. 9. ed. São Paulo: Global, 2000. 112 p. v. 1.

MARX, K.; ENGELS, F. Manifesto Comunista. 3. ed. São Paulo: Boitempo Editorial, 2002. 253 p. v. 1.

MARX, K.; ENGELS, F. Manifesto Comunista. São Paulo: Instituto José Luís e Rosa Sundermann, 2003.

NETTO, M. R. A concepção de classe em Weber e Marx e os desafios contemporâneos do sindicalismo brasileiro. Mato Grosso: Universidade Federal de Mato Grosso - UFMT, 2011. Disponível em: <http://www.joinpp.ufma. br/jornadas/joinpp2011/CdVjornada/JORNADA EIXO_2011/ESTADO_LUTAS_SOCIAIS_E_POLITICAS_PUBLICAS̄/A_CONCEPCAO__DE_ CLASSE_EM_WEBER_E_MARX_E_OS_DESAFIOS_CONTEMPORANEOS_DO_SINDICALISMO_BRASILEIRO.pdf>. Acesso em: 15 jul. 2017.

PRESTES, Z. Quando não é quase a mesma coisa: análise das traduções de Lev Seminovicht Vigostki no Brasil repercussões no campo 
educacional. Brasília: Universidade de Brasília, Faculdade de Educação, Programa de Pós Graduação em Educação, 2010. Disponível em: <https://www.cepae.ufg.br/up/80/o/ZOIA_PRESTES_-_TESE.pdf?1462533012>. Acesso em: 27 maio 2017.

REIS, C. W.; FACCI, M. G. D. Contribuições da psicologia histórico-cultural para a compreensão da velhice. Revista Eletrônica Arma da Crítica. Número 6/Outubro de 2015, p. 99-116. Disponível em < http://www.repositorio.ufc.br/bitstream/ riufc/23237/1/2015_art_cwreismgdfacci.pdf>. Acesso em: 22 jul. 2017.

SILVA, F. G. Subjetividade, individualidade, personalidade e identidade: concepções a partir da psicologia histórico-cultural. Psic. da Ed., São Paulo, 28, $1^{\circ}$ sem. de 2009, pp. 169195. Disponível em: <http://pepsic.bvsalud.org/ pdf/psie/n28/v28a10.pdf>. Acesso em: 18 jun. 2017.

TULESKI, S. C. Vygotski: a construção de uma Psicologia Marxista. Maringá: Eduem, 2008.

\section{CONSTRUCCIÓN DE LA PERSONALIDAD EN EL PERÍODO DE LA ADOLESCENCIA DE LA CLASE TRABAJADORA EN LA PERSPECTIVA DE LA PSICOLOGÍA HISTÓRICO CULTURAL}

Resumen: Esta investigación ha tenido por objetivo destacar e investigar la construcción de la personalidad en el período de la adolescencia de la clase trabajadora basado en la Psicología Histórico Cultural, subsidiada por el Materialismo Histórico Dialéctico. Este tema nos llamó la atención a través de prácticas de pasantía en un Centro de Referencia y Asistencia Social - CRAS de una ciudad del interior de Paraná. Así, hemos destacado los aspectos que diferencian las clases sociales, como las mediaciones que llegan hacia los adolescentes que residen en este contexto y que buscan formas de supervivencia por medio del trabajo.

Palabras clave: Adolescencia; Clase trabajadora; Personalidad; Psicología histórico cultural. 